\title{
Management of A Chyluria: About A Case and Review of The Literature
}

\section{Nabil Jakhlal*, Georges Comlan and TaoufikTaouil \\ Department of Urology, Mangot-Vulcin Hospital, France}

Submission: May 21, 2018; Published: July 05, 2018

*Corresponding author: Nabil Jakhlal, Department of Urology, Mangot-Vulcin Hospital, Martinique Hospital Center, France; Email: doc.nabil54@gmail.com

\begin{abstract}
Summary
Chyluria is the passage of chyle in the urine. The cause seems to be the rupture of retroperitoneal lymphatics into the pyelocaliceal system, giving urine a milky appearance. This condition, if left untreated, leads to significant morbidity. We present a case of bilateral chyluria treated by transperitoneal laparoscopic nephrolysis and discuss at the same time the epidemiological, pathophysiological, diagnostic and therapeutic characteristics of chyluria.
\end{abstract}

Keywords: Chyluria; Povidone iodine; sclerotherapy; laparoscopy; Retrograde pyelography; Lymph; Urine; Pyelocaliceal system; Haematochyluria; Renal colic; Cystoscopy; Hematuria; Wucheriabancrofti; Thoracic duct; Genitourinary tract; Lymphangiectasis; Lymphaticourinary fistula; Spontaneous remissions; Exacerbations; Urinary tract infections; Immunosuppression; Lipuria

Abbreviations: RGP: Retrograde Pyelography

\section{Introduction}

Chyluria is the passage of the lymph in the urine. It appears to be secondary to the rupture of the retroperitoneal lymphatic vessels in the pyelocaliceal system, giving the urine a milky appearance. This condition, if left untreated, causes significant morbidity due to haemato-chyluria, recurrent renal colic, acute urinary retention, nutritional problems due to protein loss and resulting immunosuppression due to lymphocyturia. Chyluria can be classified into mild, moderate or severe.
Its treatment comprises 3 components depending on the severity of the disease: conservative medical treatment, sclerotherapy by intrarenal pelvic instillation of sclerosing agents and surgical treatment.In our work, we present a case of bilateral chyluria treated by transperitoneal laparoscopic nephrolysis and at the same time discuss the epidemiological, physiopathological, diagnostic and therapeutic characteristics of chyluria.
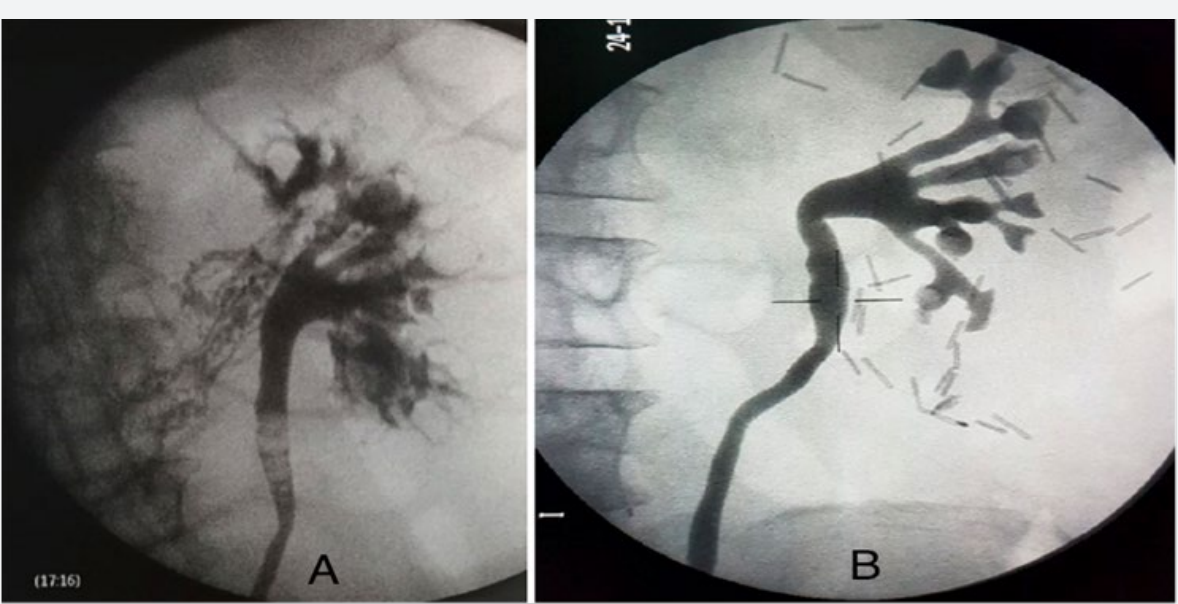

Figure 1: RGP showing multiple anastomoses between lymphatics of the left kidney and urinary tract (A) and disappearance after laparoscopic nephrolysis (B). 


\section{Global Journal of Reproductive Medicine}

Observation

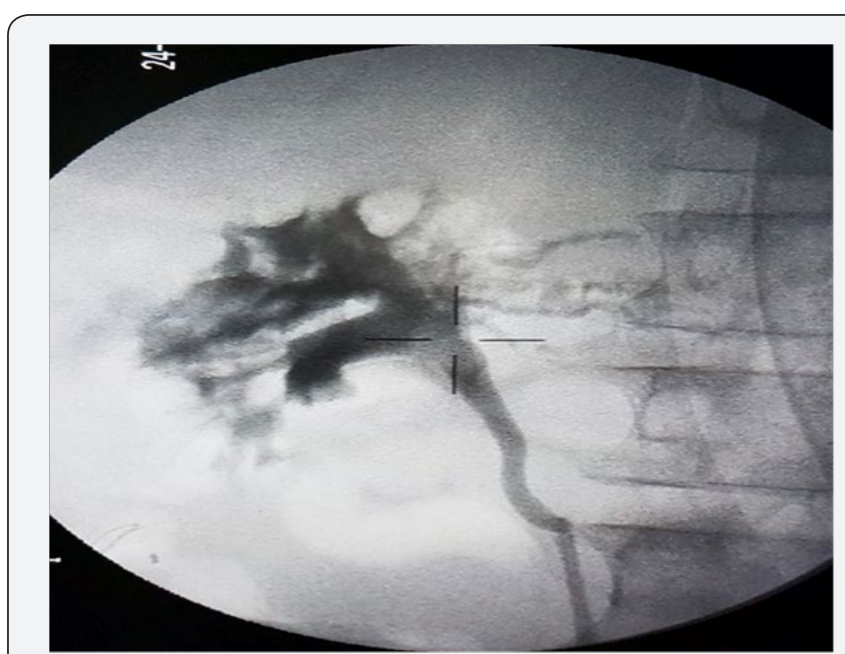

Figure 2: RGP illustrating a communication between the right upper urinary tract and the retroperitoneal lymphatics.

A 77-years-old patient from Martinique who has a history of gastric ulcer with a left inguinal hernia, admitted to our formation for the management of chronic chyluria complicated by acute urinary retention. Urine cytology was inflammatory with a negative parasitic assessment. Uroscan was normal. The cystoscopy showed very turbid urine without being able to specify the side reached. Complement with RGP revealed multiple anastomoses between the lymphatics of the left kidney and the urinary tract (Figure 1A). We opted for a transperitoneal laparoscopic with left-lymphatic disconnection. The evolution was marked by a recurrence of chyluria 6 months later. A new cystoscopy and RGP revealed a good surgical result for the left side Figure 1B with appearance of communication between the right upper urinary tract and the retroperitoneal lymphatics (Figure 2). We proceeded in the same way for the right side as the left side (a transperitoneal laparoscopic reno-lymphatic disconnection) with good clinical evolution.

\section{Discussion}

Chyluria is the consequence of the passage of the lymph in the urine giving them a milky white appearance (or milk strawberry if hematuria associated with it) because of its high content of chylomicrons[1]. Chyluria is a benign clinical condition prevalent in South East Asia like China, India, Japan, Taiwanand parts of Africa, Australia and South America [2]. The aetiology of chyluria can be classified as parasitic and non-parasitic. Parasitic infestation by Wucheriabancroftiinfestation is responsible for $>95 \%$ of parasitic chyluria in India. It occurs due to a blockage of the major retroperitoneal lymphatics and thoracic duct by the mature parasite. This leads to retrograde flow of lymph from the gut and pelvis to the lumen of the genitourinary tract, lymphangiectasis and subsequent development of urinary fistulae [3]. The most location of lymphaticourinary fistula is at the caliceal fornix but can also occur at the level of the ureter or urinary bladder $[3,4]$. This disease is characterized by spontaneous remissions and exacerbations. Among non-filarial chyluria, congenital causes, thoracic duct injuries, thoracic duct obstruction due to tumors, pregnancy, abdominal surgery are the most common causes [5].

The symptoms of chyluria are renal colic due to milky white urine with clots, dysuria, urinary retention, hematuria, and urinary tract infections. In some severe forms, the disease can lead to significant weight loss, malnutrition, hypoproteinemia and immunosuppression.Investigation of chyluria includes chemical and parasitic urinary testing for microfilariae, evaluation of renal function and nutritional status, cystoscopy and RGP in the first place. Cystoscopy performed best post-prandial after a high fat intake allows to specify the side achieved by objectifying the issue of milky urine through the meatus. The RGP can visualize opacification of paracaliceal lymphatics by reflux of the contrast product. The lymphography, although not allowing to specify the exact seat of the communication and abandoned by most authors, allows in some cases to make a surgical choice of the side to be treated first.The differential diagnosis will be with pyuria, phosphaturia or lipuria. In the latter event, the presence of large fat globules and the absence of fibrin redress the diagnosis. The absorption of 100 grams of Sudan III and 10 grams of butter gives the urine a characteristic bright orange color.

Chyluria can be classified according to its severity into three grades: mild (intermittent milky urine, no clots, no weight loss, a single calyx involved on RGP), moderate (intermittent or continuous milky urine with occasional clots, no weight loss, two calyces involved on RGP) and severe (continuous milky urine with clots, weight loss, most of the calyces involved on RGP) [6]. The therapeutic management of a patient with chyluria depends on the severity of the disease. Minimal and moderate cases of chyluria may be conservative, including diet modification and anti-filarial drugs $[7,8]$. Retrograde renal pelvic instillation of sclerosing agents has become the most common form of treatment for chyluria [9]. Its mechanism of action is to induce an inflammatory reaction, a chemical lymphangitis with subsequent closure of pyelo-lymphatic fistulas by fibrosis [9]. Different types of sclerosing agents were used: 1-3\% silver nitrate, $1-25 \%$ sodium iodide, $10-25 \%$ potassium bromide, $50 \%$ dextrose, $76 \%$ Urograffin, and 22-25\% hypertonic saline. Silver nitrate was one of the most important sclerosing agents used for many years; however, its use has been restricted because of its multiple side effects, such as interstitial nephritis, ureteral stenosis, papillary necrosis, renal failure, and even death $[9,10]$.

Many authors have described the use of Povidone iodine as a sclerosing agent in the treatment of chyluria because of its high efficacy reaching 81 to $100 \%$ with a recurrence rate of 5 to $17 \%$ [11-14], its antibacterial properties, its availability and its minimal side effects $[11,12,15]$. Povidone iodine as a sclerosing agent for the treatment of chyluria has been used either alone or in combination with other agents, and also as a single or multiple instillations $[12,13,16]$. However, there is no standard protocol 


\section{Global Journal of Reproductive Medicine}

defined to describe the optimal dose, duration and number of instillations.

If chyluria is more severe or persistent, more radical therapeutic measures should be taken such as lympho-venous disconnection surgery, or nephrectomy and autotransplantation in very severe cases [17]. Renal-lymphatic surgical disconnection seems to be accepted by most authors as the standard surgical treatment giving a satisfactory success rate (98\%) and lasting long-term results $[18,19]$. The commonly described technique includes nephrolympholysis, ureterolympholysis, renal hilar lymphatic vessels stripping and fasciectomy until the kidney is retained only by the renal vessels and the ureter. This poses a risk of nephroptosis and renal torsion, which is prevented by nephropexy at the end [1,8,20-22]. This procedure can be performed by open surgery or laparoscopy. Retroperitoneal renolymphatic disconnection provides the same clinical outcome as open surgery with minimal invasion, sparing operative time, less blood loss, less postoperative drainage, and faster recovery [6,23-25].

\section{Conclusion}

The treatment of chronic chyluria is complex. Its medical treatment is most often insufficiant and the reno-lymphatic disconnection remains the reference treatment. Sclerotherapy is an effective and less invasive alternative to surgical treatment. The choice of the sclerosing agent is now in favor of the use of Povidone iodine which has an equivalent efficiency to silver nitrate but with fewer complications and simpler preparation. The effectiveness of this treatment must be evaluated in the long term.

\section{References}

1. Moufid K, Méjean A, Balian C, Bazin JP, Dufour B, et al. (2005) Laparoscopic kidney release for refractory chyluria. Prog Urol 15(1): 72-74.

2. Hemal AK, Gupta NP (2002) Retroperitoneoscopic lymphatic management of intractable chyluria. J Urol 167(6): 2473-2476.

3. Diamond E, Schapira HE (1985) Chyluria-a review of the literature. Urology 26(5): 427-431.

4. Akisada M, Tani S (1968) Filarial chyluria in Japan. Lymphography, etiology and treatment in 30 cases. Radiology 90(2): 311-317.

5. Lazarus JA, Marks MS (1946) Non-parasitic chyluria with special reference to traumatic chyluria. J Urol 56(2): 246-258.

6. Date A, John TJ, Chandy KG, Rajagopalan MS, Vaska PH, et al. (1981) Abnormalities of the immune system in patients with chyluria. Br J Urol 53(4): 384-386.

7. Henry HY, Leong Ch, Ong GB (1978) Chyluria: result of surgical treatment in 50 cases. J Urol 119(1):104-107.

8. Zhang X, Ye ZQ, Chen Z, Chen ZQ, Zhu QG, et al. (2003) Comparison of open surgery versus retroperitoneoscopic approach to chyluria. J Urol 169(3): 991-993.

9. Sabnis RB, Punekar SV, Desai RM, Bradoo AM, Bapat SD (1992) Instillation of silver nitrate in the treatment of chyluria. Br J Urol 70(6): 660-662.

10. Dash SC, Bhargav Y, Saxena S, Agarwal SK, Tiwari SC, et al. (1996) Acute renal failure and renal papillary necrosis following instillation of silver nitrate for treatment of chyluria. Nephrol Dial Transplant 11(9): 18411842.

11. Shanmugam TV, Prakash JV, Sivashankar G (1998) Povidone iodine used as a sclerosing agent in the treatment of chyluria. Br J Urol 82(4): 587.

12. Nandy PR, Dwivedi US, Vyas N, Prasad M, Dutta B, et al. (2004) Povidone iodine and dextrose solution combination sclerotherapyin chyluria. Urology 64(6): 1107-1109.

13. Ramana Murthy KV, Jayaram Reddy S, Prasad DV, Purusotham G (2010) Povidone iodine instillation into the renal pelvis in the management of chyluria: our experience. Urol Int 84(3): 305-308.

14. Shrestha A, Verma R (2014) Is single dose povidone iodine sclerotherapy effective in chyluria? Int Urol Nephrol 46(4):1059-1062.

15. Goel S, Mandhani A, Srivastava A, Kapoor R, Gogoi S, et al. (2004) Is povidone iodine an alternative to silver nitrate for renal pelvic instillation sclerotherapy in chyluria? BJU Int 94(7):1082-1085.

16. Sharma G, Chitale V, Karva R, Sharma A, Durug AB (2008) Fluoroscopy guided instillation therapy in chyluria using combination of povidone iodine with contrast agent. Is a single instillation sufficient? Int Braz J Urol 34(3): 270-275.

17. Sachit S, AshokKumar H (2009) Chyluria-an overview. Nephro Urol Mon 1(1):14-26.

18. Punekar SV, Kelkar AR, Prem AR, Deshmukh HL, Gavande PM (1997) Surgical disconnection of lymphorenal communication for chyluria: a 15-year experience. BJU 80(6): 858-863.

19. Yu HH, Leong CH, Ong GB (1978) Chyluria: result of surgical treatment in 50 cases. J Urol 119(1): 104-107.

20. Hemal AK, Kumar M, Wadhwa SN (1999) Retro-peritoneoscopic nephrolympholysis and ure-terolysis for management of intractable filarial chyluria. J Eourol 13(7): 507-511.

21. Zhang X, Zhu QG, Ma X, Zheng T, Li HZ, et al. (2005) Renal pedicle lymphatic disconnection for chyluria via retroperitoneoscopy and open surgery: report of 53 cases with followup. J Urol 174(5): 1828-1831.

22. Lan WH, Jin FS, Wang LF, Zhu FQ (2007) A comparison of retroperitoneoscopic and open surgical renal pedicle lymphatic disconnection for the treatment of serious filarial chyluria. Chin Med J 120: 932-934.

23. Chiu AW, Chen MT, Chang LS (1995) Laparoscopic nephrolysis for chyluria: case report of long-term success. J Endourol 9(4): 319-322.

24. Gomella LG, Shenot P, Abdel-Meguid TA (1998) Extraperitoneal laparoscopic nephrolysis for the treatment of chyluria. Br J Urol 81(2): 320-321.

25. Zhang Y, Zeng J, Zhang K, Jin F, Ye J, et al. (2012) Surgical Management of Intractable Chyluria: A Comparison of Retroperitoneoscopy with Open Surgery. Urol Int 89(2): 222-226. 

(C) C. $\begin{aligned} & \text { Commons Attribution 4.0 License } \\ & \text { DoI: } 10.19080 / G J O R M .2018 .05 .555656\end{aligned}$

\section{Your next submission with Juniper Publishers} will reach you the below assets

- Quality Editorial service

- Swift Peer Review

- Reprints availability

- E-prints Service

- Manuscript Podcast for convenient understanding

- Global attainment for your research

- Manuscript accessibility in different formats ( Pdf, E-pub, Full Text, Audio)

- Unceasing customer service

Track the below URL for one-step submission https://juniperpublishers.com/online-submission.php 